Article

\title{
Identifying Social Impacts in Product Supply Chains: Overview and Application of the Social Hotspot Database
}

\author{
Catherine Benoit-Norris $^{1,2, *}$, Deana Aulisio Cavan ${ }^{2}$ and Gregory Norris ${ }^{1}$ \\ 1 New Earth, P.O. Box 507, York Beach, ME 03910, USA; E-Mail: greg.norris@earthster.org \\ 2 University of New Hampshire, Durham, NH 03824, USA; E-Mail: deana.aulisio@unh.edu \\ * Author to whom correspondence should be addressed; E-Mail: catherine.benoit@earthster.org; \\ Tel.: +1-207-351-1895; Fax: +1-207-636-8021.
}

Received: 9 July 2012; in revised form: 13 August 2012 / Accepted: 15 August 2012 /

Published: 24 August 2012

\begin{abstract}
One emerging tool to measure the social-related impacts in supply chains is Social Life Cycle Assessment (S-LCA), a derivative of the well-established environmental LCA technique. LCA has recently started to gain popularity among large corporations and initiatives, such as The Sustainability Consortium or the Sustainable Apparel Coalition. Both have made the technique a cornerstone of their applied-research program. The Social Hotspots Database (SHDB) is an overarching, global database that eases the data collection burden in S-LCA studies. Proposed "hotspots" are production activities or unit processes (also defined as country-specific sectors) in the supply chain that may be at risk for social issues to be present. The SHDB enables efficient application of S-LCA by allowing users to prioritize production activities for which site-specific data collection is most desirable. Data for three criteria are used to inform prioritization: (1) labor intensity in worker hours per unit process and (2) risk for, or opportunity to affect, relevant social themes or sub-categories related to Human Rights, Labor Rights and Decent Work, Governance and Access to Community Services (3) gravity of a social issue. The Worker Hours Model was developed using a global input/output economic model and wage rate data. Nearly 200 reputable sources of statistical data have been used to develop 20 Social Theme Tables by country and sector. This paper presents an overview of the SHDB development and features, as well as results from a pilot study conducted on strawberry yogurt. This study, one of seven Social Scoping Assessments mandated by The Sustainability Consortium, identifies the potential social hotspots existing in the supply chain of strawberry yogurt. With this knowledge, companies that manufacture or sell yogurt can refine their data collection efforts in order to put their social responsibility performance in perspective and
\end{abstract}


effectively set up programs and initiatives to improve the social conditions of production along their product supply chain.

Keywords: Social Hotspot Database; Social Life Cycle Assessment; social impacts of products; supply chain; corporate social responsibility

\section{Introduction}

Consumers are more frequently questioning where, by whom, and under what conditions their products are being sourced and produced. Transparency, in economic theory, implies providing key information to help stakeholders make decisions, which in turn creates incentives for businesses to align their practices with the public's priorities [1]. With the complexity of globalized production and consumption, a great deal of transparency is lost, which can result in unintended and overlooked social and environmental impacts.

A socially responsible company considers the impacts of its products beyond its own sphere of local operation and within its true triple bottom line (including the externalities), with a life cycle perspective [2]. Referred to as "supply chain sustainability", the approach is defined as being the management of environmental, social and economic impacts, and the encouragement of good governance practices, throughout the lifecycles of goods and services [3]. Nevertheless, supply chains are extremely elaborate. Even though efficient and market responsive supply chains are becoming key to succeed in the globalized system of outsourced production and trade, for the most part, companies are still learning to manage extended supply chains. Stakeholders now demand accountability for behaviors that encompass several tiers of supply chain actors, over which the firm has varying degrees of control [4]. Corporations, who are somewhat unaware of these social impacts, are now under scrutiny and increased pressure to uncover and divulge this information. Passed just last year in California, the Supply Chain Transparency Act requires companies to identify the forced and child labor risks of their supply chains [5]. Moreover, Risk assessment and Due Diligence are some of the first recommended steps of a supply chain social responsibility program [6,7].

In an effort to bring this type of social sustainability information to the fore, The Sustainability Consortium mandated New Earth to apply its new and innovative Social Hotspots Database (SHDB) to the supply chains of several product categories. New Earth is a not-for-profit organization whose mission is to stimulate sustainable development of companies, communities, and individuals. The Sustainability Consortium is a membership organization made up of diverse participants, primarily multi-national corporations interested in enhancing sustainability through and supporting research of product life cycle assessments (LCA). The objective of New Earth was to test the proficiency of the Social Hotspots Database in assessing product category supply chains' social risks. This paper discusses the how and why of the SHDB before reporting results from the Social Scoping Assessment on Strawberry Yogurt. 


\subsection{The Development and Operationalization of Social LCA}

LCA is a technique, developed in the late sixties and first standardized in the nineties, that is used to quantify environmental impacts of a product or service over its lifetime, including raw material extraction, manufacture, distribution, use, and disposal. The methodology, standardized by ISO 14040 [8], aggregates inputs and outputs of resources and chemicals to air, water, and soil into several environmental impact categories, such as global warming, resource depletion, human health, and ecosystem services.

In Environmental LCA, with the exception of the impact category of human health, which considers chemicals released to the environment indirectly affecting people's physical constitution, overall social wellbeing of a product or unit process is not assessed [9]. Social LCA intends to add in critical indicators of human wellbeing that are influenced by processes or companies in supply chains, such as worker's rights, community development, consumer protections, and societal benefits.

In 2009, after a five-year process with participation from over 70 international experts, the United Nations Environment Program (UNEP) and the Society of Environmental Toxicology and Chemistry (UNEP/SETAC) Life Cycle Initiative published the Guidelines for Social Life Cycle Assessment of Products (The Guidelines) [10]. One of the objectives of the working group was to establish a consensus on how social impacts may be best captured and integrated into the existing life cycle assessment framework in order to move towards the development of Life Cycle Sustainability Assessment (LCSA). Hence, by combining S-LCA with Environmental LCA and Life Cycle Costing - a method that takes into account costs incurred over the entire supply chain, use phase, and end-of-life - a truly holistic representation of the three pillars of sustainability of products can be assessed [11,12]. A more recent publication issued by UNEP/SETAC introduced the concepts of LCSA [13]. Essentially, this type of assessment augments decision-makers' awareness of more sustainable life cycle stages, supports stakeholders looking for implications of a product's life cycle for the environment and the society, and offers guidance to enterprises and people who are trying to increase the environmental, economic and social benefits for society and local communities.

A typical product system may include over a thousand unit processes. Therefore, there is an important need for prioritization of unit processes in conducting an S-LCA. Otherwise, it can rapidly become very costly and time consuming, and often not relevant, to collect data on-site at every organization involved in the production, use and disposal of a good or a service [9].

The Guidelines for S-LCA of products recommended the development of methods that prioritize the most important unit processes (i.e., hotspots) in supply chains to collect accurate data for. Hotspots are production activities in the product life cycle that provide a higher opportunity to address issues of concern (e.g., human and worker rights, community well-being), as well as highlight potential risks of violations, damage to reputation, or issues that need to be considered when doing business in a specific sector and country [10].

Not only can social indicator data be used to identify the most important countries and sectors to be aware of in a supply chain, but also the use of an "activity variable" such as worker hours or value added can be used to prioritize hotspots and assist in developing boundary conditions in the life cycle. Since supply chains are so complex, setting boundary conditions, such as only including unit processes or Country Specific Sectors (CSS) contributing to greater than $0.1 \%$ of the worker hours of the supply 
chain, are necessary. Consequently, social impacts associated with those unit processes or CSSs representing less than $0.1 \%$ of the total worker hours are deemed not contributing significantly to the overall life cycle social impacts [9].

\section{Methods}

\subsection{Global Data to Visualize Social Impacts in Supply Chains}

The Social Hotspot Database (SHDB) project has developed the recommended prioritization inventory tool for S-LCA over a three-year period. This tool can be used by: S-LCA practitioners and consultants, academics and policy advisors, Sustainability and Ethical Compliance corporate managers, consumers and consumer advocacy groups, NGO's, governments and intergovernmental organizations as well as investors. Its features include: the ability to generate geographically specific supply chains models and the ability to estimate the labor intensity by economic sector of activity, systematic and consistent methodology, transparent compilation and interpretation of a large number of publicly available data, and diverse applications not necessarily specific to S-LCA. Users of the SHDB are able to:

- Prioritize site-specific data collection and audits,

- Inform product category and ingredient sustainability assessment,

- Inform Socially Responsible purchasing process (e.g., questions to be asked for sourcing),

- Provide perspective and context to site-specific assessment results and sustainability reporting,

- Inform and report about sponsored programs designed to improve the social conditions of production,

- Inform and report about governmental policy and programs,

- Assess/report the scope of a certification or social footprint results, and

- Educate about the social conditions of production.

The Social Hotspots Database is made up of country and sector-specific indicator tables to help identify hotspots, the countries and sectors of concern, in supply chains based on potential social impacts. It is also combined with a model to determine the countries and sectors with the highest share of worker hours. Twenty Social Theme Tables have been constructed for the database. The Social Themes were chosen based on recommendations in The Guidelines, which were informed by the International Policy Frameworks (International Conventions, Covenants and Declarations), and by New Earth's esteemed advisory board. The Tables include indicator data and characterized risk for social impacts such as forced labor, prohibition of freedom of association, excessive working time, and lack of community services, to name a few (Table 1). For all of these social issues, opportunity exists to make progress or advancement, in particular to establish initiatives or to create a market to improve negative social conditions. 
Table 1. Characterized Social Issues by Social Theme and Category.

\begin{tabular}{|c|c|c|c|}
\hline Category & Social Theme (Name of Table) & Data Indicator & Characterized Issue \\
\hline \multirow{23}{*}{$\begin{array}{l}\text { Labor Rights } \\
\text { and Decent } \\
\text { Work }\end{array}$} & \multirow{5}{*}{ Labor Laws/Conventions } & Number of Labor Laws & Risk of Country not passing Labor Laws \\
\hline & & Number of Labor Laws by sector & Risk of Country not passing Labor Laws by Sector \\
\hline & & Number of Labor Conventions ratified (out of 81 possible) & Risk of Country not adopting Labor Conventions \\
\hline & & Number of Labor Conventions ratified by sector & Risk of Country not adopting Labor Conventions by Sector \\
\hline & & Year of last Minimum Wage Update & Risk of Minimum Wage not being updated \\
\hline & \multirow{6}{*}{ Wage Assessment } & $\begin{array}{l}\text { Minimum Wages (USD) } \\
\text { Average Unskilled Wages (USD) in country }\end{array}$ & Risk of Country Average Wage being $<$ Minimum Wage \\
\hline & & $\begin{array}{l}\text { Non-Poverty Guideline (USD) } \\
\text { Average Unskilled Wages (USD) in country }\end{array}$ & $\begin{array}{l}\text { Risk of Country Average Wage being }<\text { Non-Poverty } \\
\text { Guideline }\end{array}$ \\
\hline & & Minimum Wages (USD) & \multirow[b]{2}{*}{ Risk of Sector Average Wage being $<$ Minimum Wage } \\
\hline & & Average Unskilled Wages (USD) by sector & \\
\hline & & Non-Poverty Guideline (USD) & \multirow{2}{*}{ Risk of Sector Average Wage being $<$ Non-Poverty Guideline } \\
\hline & & Average Unskilled Wages (USD) by sector & \\
\hline & Population living in Poverty & Percent of Population living on $<\$ 2 /$ day & Risk of Population living on $<\$ 2 /$ day \\
\hline & \multirow{2}{*}{ Child Labor } & Child Labor $\%$ in country & Risk of Child Labor in country \\
\hline & & Child Labor $\%$ by sector & Risk of Child Labor by sector \\
\hline & \multirow{2}{*}{ Forced Labor } & Qualitative & Risk of Forced Labor in country \\
\hline & & Qualitative & Risk of Forced Labor by sector \\
\hline & \multirow{2}{*}{ Excessive Working Time } & Percent working $>48$ hours/week in country & Risk of Population working $>48$ hours/week in country \\
\hline & & Qualitative & Risk of Population working $>48$ hours/week by Sector \\
\hline & \multirow{3}{*}{$\begin{array}{l}\text { Freedom of Association, } \\
\text { Collective Bargaining, } \\
\text { Right to Strike } \\
\end{array}$} & Qualitative & Risk of not having Freedom of Association Rights \\
\hline & & Qualitative & Risk of not having Collective Bargaining Rights \\
\hline & & Qualitative & Risk of not having the Right to Strike \\
\hline & \multirow{2}{*}{ Unemployment } & Unemployment Average \% from 2000-2009 & Risk of High Unemployment in country \\
\hline & & Unemployment $\%$ by sector & Risk for High Unemployment by sector \\
\hline Governance & Legal System & $\begin{array}{l}\text { World Bank Worldwide Governance } \\
\text { Indicator-Rule of Law } \\
\text { Bertelsmann Transformational Index - } \\
\text { Rule of Law, Independent Judiciary } \\
\text { CIRI Human Rights Index-Independent Judiciary } \\
\text { Global Integrity Index-Judicial Accountability } \\
\text { Global Integrity Index-Rule of Law } \\
\text { Global Integrity Index-Law Enforcement } \\
\text { World Justice Project-Average }\end{array}$ & Risk of Fragility in Legal System \\
\hline
\end{tabular}


Table 1. Cont.

\begin{tabular}{|c|c|c|c|}
\hline Category & Social Theme (Name of Table) & Data Indicator & Characterized Issue \\
\hline \multirow{13}{*}{ Human Rights } & \multirow{5}{*}{ Indigenous Rights } & Presence of indigenous population, $\mathrm{X}$ & Not characterized \\
\hline & & Indigenous Population, $\%$ & Amount of Indigenous Population \\
\hline & & $\begin{array}{l}\text { ILO Convention adopted for Indigenous, Y or N } \\
\text { UN Declaration for Indigenous, endorsed (Y), abstained } \\
\text { (A), against (N) }\end{array}$ & $\begin{array}{l}\text { Risk of country not adopting Indigenous ILO convention and } \\
\text { UN Declaration }\end{array}$ \\
\hline & & Number of Laws enacted to protect Indigenous & Risk of country not passing Laws to protect Indigenous \\
\hline & & Qualitative & Risk for Indigenous Rights Infringements by Sector \\
\hline & \multirow{6}{*}{ Gender Equity } & $\begin{array}{l}\text { Social Institutions and Gender Index } \\
\text { Global Gender Gap } \\
\text { World Bank Gender Development Indicator } \\
\text { World Bank Gender Empowerment Index } \\
\text { CIRI Human Rights Index-Economic } \\
\text { CIRI Human Rights Index-Political } \\
\text { CIRI Human Rights Index-Social }\end{array}$ & Risk of Gender Inequity \\
\hline & & $\begin{array}{l}\text { Adolescent fertility rate (births per } 1000 \text { women } \\
\text { ages } 15-19 \text { ) }\end{array}$ & Not characterized \\
\hline & & Fertility rate, total (births per woman) & Not characterized \\
\hline & & $\begin{array}{l}\text { Share of women employed in the nonagricultural } \\
\text { sector ( } \% \text { of total nonagricultural employment) }\end{array}$ & Not characterized \\
\hline & & $\begin{array}{l}\% \text { Unemployment, ( } \% \text { of female labor force } \\
\text { unemployed } / \% \text { of male labor force unemployed) }\end{array}$ & Not characterized \\
\hline & & $\%$ of women workers $v s$. men by sector & Risk of Gender Inequity by sector \\
\hline & \multirow[t]{2}{*}{ High Conflict Zones } & $\begin{array}{l}\text { Heidelberg Conflict Barometer-\# of conflicts } \\
\text { Heidelberg Conflict Barometer-maximum } \\
\text { intensity of conflicts (1-5) } \\
\text { Heidelberg Conflict Barometer-change } \\
\text { in conflicts (positive = worsening) } \\
\text { Number of Refugees - UN Refugee Agency (000's) } \\
\text { Center for Systemic Peace Indicator } \\
\text { Minority Rights Group Indicator } \\
\text { Top Risers from last year in Minority } \\
\text { Rights Group Indicator, X }\end{array}$ & Risk for High Conflict \\
\hline & & Qualitative & Risk for High Conflict specific to sectors \\
\hline
\end{tabular}


Table 1. Cont

\begin{tabular}{|c|c|c|c|}
\hline Category & Social Theme (Name of Table) & Data Indicator & Characterized Issue \\
\hline \multirow{11}{*}{ Human Rights } & \multirow{11}{*}{$\begin{array}{l}\text { Human Health - } \\
\text { Communicable Diseases \& } \\
\text { Other Health Risks } \\
\text { besides Disease }\end{array}$} & Life expectancy at birth (years) 2008 & Risk of low life expectancy \\
\hline & & Mortality rates for injuries (per 100,000 population) 2004 & Risk of high mortality rates due to injury \\
\hline & & $\begin{array}{l}\text { Proportion of undernourished } \% \text { of total } \\
\text { population, }(-)=<5 \% 2005-2007\end{array}$ & Risk of high undernourishment \\
\hline & & $\begin{array}{l}\text { Deaths due to indoor and outdoor air and } \\
\text { water pollution, per million } 2004\end{array}$ & Risk of death due to air and water pollution \\
\hline & & $\begin{array}{l}\text { Population affected by natural disasters, } \\
\text { ave per year per million } 2000-2009\end{array}$ & Risk of death due to natural disasters \\
\hline & & Cases of HIV (per 1000 adults $15-49$ years) 2010 & Risk of HIV 2010 \\
\hline & & Cases of Tuberculosis (per 100,000 population) 2008 & Risk of Tuberculosis 2008 \\
\hline & & Cases of Malaria (per 100,000 population) 2008 & Risk of Malaria 2008 \\
\hline & & Cases of Dengue Fever (per 100,000 population) 2005 & Risk of Dengue Fever, 2005 \\
\hline & & Cases of Cholera 2008 & Risk of Cholera 2008 \\
\hline & & $\begin{array}{l}\text { Mortality rates from communicable diseases } \\
\text { (per } 100,000 \text { population) } 2004\end{array}$ & Risk of mortality from communicable diseases \\
\hline \multirow{6}{*}{$\begin{array}{l}\text { Community } \\
\text { Infrastructure }\end{array}$} & \multirow{3}{*}{ Children Out of School } & Children out of School—male & Risk of Children not attending School-male \\
\hline & & Children out of School—female & Risk of Children not attending School-female \\
\hline & & Children out of School一total & Risk of Children not attending School-total \\
\hline & $\begin{array}{l}\text { Access to Improved Drinking } \\
\text { Water }\end{array}$ & $\begin{array}{l}\text { Access to Improved Drinking Water, } \% \text { - rural } \\
\text { Access to Improved Drinking Water, } \% \text { - urban } \\
\text { Access to Improved Drinking Water, } \% \text { - total }\end{array}$ & $\begin{array}{l}\text { Risk of not having access to Improved Drinking Water-rural } \\
\text { Risk of not having access to Improved Drinking Water-urban } \\
\text { Risk of not having access to Improved Drinking Water-total }\end{array}$ \\
\hline & Access to Improved Sanitation & $\begin{array}{l}\text { Access to Improved Sanitation, } \% \text {-rural } \\
\text { Access to Improved Sanitation, } \% \text { - urban } \\
\text { Access to Improved Sanitation, } \% \text { - total }\end{array}$ & $\begin{array}{l}\text { Risk of not having access to Improved Sanitation-rural } \\
\text { Risk of not having access to Improved Sanitation-urban } \\
\text { Risk of not having access to Improved Sanitation-total }\end{array}$ \\
\hline & Access to Hospital Beds & Access to Hospital Beds-\# beds/1000 pop & Risk of not having Access to Hospital Beds \\
\hline
\end{tabular}


Regional specificity is a major consideration when collecting indicator data for the SHDB. Location information available in Environmental LCA unit process databases often depicts the data origin instead of where the production activity is likely to be based. General knowledge on where the production activities are taking place is much more necessary for Social LCA because of societal, political, and cultural differences. Ekvall [14] highlighted the relevance of national statistics to assess the potential social impacts of supply chains. The SHDB Social Theme Tables list indicator data and qualitative information that is characterized for the level of risk (low, medium, high, and very high) for 191 countries and 57 sectors. Sector data is not applicable or available for all indicators but is used when relevant and accessible, like for child labor and wage rates.

The development of the SHDB Social Theme Tables uses a data driven approach. First, a review of available data sources is conducted. Global indicator and qualitative data is extracted from various international organizations with strong statistical agencies such as the World Health Organization, the International Labor Organization, the World Bank, and many others. Second, a decision is made on whether it is appropriate to research sector-level data for the theme investigated. Third, the data to use are chosen based on a set of criteria, which include:

1) Comprehensiveness (\# of country and sectors for which data is available),

2) Legitimacy of the data source,

3) Reliability of method(s) used to collect data by the source,

4) Quantitative indicators,

5) Relevance to the theme investigated.

In total over 400 publicly available data sources have been reviewed and over 200 incorporated to the database.

After data collection, characterization methods are developed in order to present the level of risk. The vast majority of characterization models for the Social Theme Tables have been based on even distributions of the data, where quartiles were defined as low, medium, high, and very high risk. In a few exceptions, for example, Access to Hospital Beds, Drinking Water and Sanitation, data from the literature is used to calibrate the characterization. To a lesser extent, expert judgment from New Earth's advisory board has provided insights into the characterization methods. In the future, it is foreseen to call on further expert insights and literature review for calibrating the characterization models.

The tables vary by their use of qualitative and/or quantitative data, by the number of sources used, and by the number of indicators used to create individual or combined characterized risks. Therefore each Social Theme Table is more or less unique. Table 1 outlines the Categories that each Social Theme Table falls into as well as the Indicators used and related Characterized Issues.

The second major component of the SHDB besides the Social Theme Tables is a Worker Hours Model that ranks CSS within supply chains by labor intensity. Worker hours are a representation of where people are most active in supply chains. In order to generate the Worker Hours Model, a Global IO model derived from the Global Trade Analysis Project database is used [15]. This model from GTAP is preferred because it is the IO model that currently presents data for the greatest number of countries and for the greatest number of sectors. Whereas the Social Theme Tables' results are available for 191 countries, the GTAP model enables the modeling of 113 countries and regions only. Several regions aggregate countries for which specific IO information was not available for the model. 
The Worker Hours Model ranks CSS within supply chains by labor intensity not dollar values. Therefore, in order to assess worker hours, data provided in the Global IO model on payment of wages to workers in dollars per dollar of product output was divided by wage rate data in dollars per hour. Wage rate data was obtained from International Labour Organisation's Laborsta Database, the United Nations Industrial Development Organization, Organization for Cooperation and Development's Stat Extracts and the Food and Agriculture Organization's Rural Income Generating Activities (RIGA) Database [16-19]. Modeling of the supply chain is achieved by looking at the worker hours share contributed from each of 6441 (113 countries/regions by 57 sectors) CSS for a defined amount of dollars of output for a defined primary CSS. For example, it details the worker hours contribution from all CSS for the amount of 1 million dollars worth of Dairy Products made in the U.S.

Using both the Worker Hours Model and the Social Theme Tables, it is possible to guide the decision-making process to help determine if and where to conduct case-specific assessments. This cost and time-efficient system including ranking by importance with an activity variable, hotspot assessment with the Social Theme Tables, and a limited number of site-specific visits represents a promising approach to S-LCA suggested by The Guidelines [10].

\subsection{An Index to Identify Hotspots}

Even by prioritizing the CSS in a supply chain by worker hours, with over 50 characterized social issues for 20 Social Themes, the amount of data is difficult to assess for decision-making. In order to better understand the vast amount of social impact information for each CSS, a Social Hotspot Index was calculated and used to help rank CSS and identify hotspots in the supply chain. The Index was constructed by first weighing the level of risk identified for each Social Issue. A zero was assigned to social issues with low risk, a 1 was assigned to those that are medium, a 2 to those with high risk, and a 3 for those with very high risk. Summing across all social issues resulted in a total number of weighted hotspot issues to be aware of when working in that country and sector. Thus, social issues are not compared against each other; they are cumulative across a CSS. All issues are weighted equally in the sum and all are considered a risk or negative impact. Positive impacts are not assessed with the Social Hotspot Index.

The index then incorporated the share of worker hours for each CSS in the Worker Hours ranking by increasing the index for the CSS with the highest share of worker hours. In this way, the CSS that are contributing the most to the life cycle in terms of worker hours are valued more and their risk level, as a hotspot, increases. For those with greater than or equal to $1 \%$ of the total worker hours per million dollars of product, the weighted sum of social issues was increased by $30 \%$; those with greater than or equal to $0.2 \%$ of the total worker hours per million dollars were increased by $20 \%$; and those with greater than or equal to $0.1 \%$ of the total worker hours per million dollars were increased by $10 \%$.

Next, the final sum was divided by the highest possible score for that CSS, which discounts for the issues that have no data (nd) or are not applicable (na), and multiplied by a factor of 100 . In some cases, the final score was greater than 100 (due to the percentage increase for CSS with the greatest share of worker hours). These were rounded down to 100 so that the maximum Index a CSS could achieve is 100 . 
For the Social Scoping Assessments that were developed for The Sustainability Consortium and described in detail in Section 3, two lists of CSS were tested within the SHDB model. The first list of CSS was based on the share of worker hours, where the top ranked CSS were evaluated using the Social Theme Tables to identify the CSS with the greatest risk. A second list was based on an external literature review that identified other important CSS in the supply chain that did not rank high for worker hours. These CSS were also tested with the Tables to identify high risk CSS as potential hotspots. Risk results from testing each CSS from the two lists with the Social Theme Tables and worker hour ranking were used to calculate a Social Hotspot Index, which was then used to rank the CSS and identify potential hotspots.

\section{Results and Discussion}

To test the proficiency of the SHDB, seven Social Scoping Assessments (SSAs) were performed on various product categories for The Sustainability Consortium. These pilot tests included orange juice, strawberry yogurt, wheat cereal, shampoo, laundry detergent, hard surface cleaner, and laptop. For this paper, the SSA for strawberry yogurt is highlighted. The SSA is an extensive report that investigates the history, production methods, ingredient formulas, and market for strawberry yogurt produced in the U.S. [20]. Amodeling assessment, which includes an analysis of the supply chain worker hours, is performed with the SHDB to determine the major social issues and hotspots in the supply chain. In order to verify and support that assessment, a literature review investigates relevant social issues for the primary ingredients in strawberry yogurt. In addition, a list of the main media campaigns, initiatives, and certifications that raise awareness and work towards positive change to social issues in the sectors related to this product are highlighted. This section provides a summarized overview of the full report which can be found on the SHDB website [20].

Strawberry Yogurt is an agricultural product manufactured in large volumes in the U.S. Yogurt production in 2010 was 4.2 billion pounds at 116 processing plants [21]. The industry relies on two primary sectors: dairy products and fruits and vegetables in the U.S. However, the results of this study indicate that many more sectors and countries are at play in the supply chain, or cradle-to-gate life cycle, of fruit yogurt. While milk and strawberries are the primary ingredients by weight, a variety of additional ingredients including sugars, bacterial cultures, and stabilizers, such as food starch, gelatin, guar gum, or locust bean gum, are also typically added [22]. A system diagram of strawberry yogurt indicates many other life cycle inputs related to other sectors. These include the growing of corn to feed dairy cows and the fertilizers and pesticides produced by the chemical sector used on strawberries (or corn) in the fields [20].

\subsection{Worker Hours Ranking for the Dairy and Fruit and Vegetable Sectors in the U.S.}

A total matrix of 113 countries by 57 sectors, or 6,441 CSS, are evaluated in the Worker Hours Model developed from the GTAP database. According to the results of the worker hours assessment based on a functional unit of US\$ $1 \mathrm{M}$ of strawberry yogurt in the U.S., 95\% of the worker hours are within the top 488 ranked CSS for the dairy product sector and the top 292 for the vegetable and fruits sector. The worker hours are therefore, more distributed across sectors for the dairy products sector compared to the vegetables and fruits sector. 
The top CSS with the greatest share of worker hours in the total and unskilled labor force for US\$ $1 \mathrm{M}$ of dairy products produced in the U.S. is the dairy products sector in the U.S. For skilled labor, the most worker hour intense CSS is business services in the U.S. The dairy product sector is responsible for nearly $20 \%$ of the total and unskilled worker hours, and only $9 \%$ of the skilled labor. The India oil seed sector is the only CSS from another country to appear on the top ten CSS with the most worker hours. This sector is most likely used in producing feed for dairy cows. The other important U.S. sectors with regards to worker hours for dairy products include business services and retail operations, raw milk production, financial intermediation, construction, and transport. The top ten CSS represent $61 \%$ of the total worker hours in the dairy product supply chain.

The top CSS with the greatest share of worker hours in the total labor force for production of US\$ $1 \mathrm{M}$ of vegetables and fruits in the U.S. is vegetables and fruits in the U.S., which is responsible for $34 \%$ of the total worker hours, $38 \%$ of the unskilled worker hours, and $8 \%$ of the skilled labor in the supply chain. The important sectors in the U.S. with regards to worker hours for vegetables and fruits include business services and retail operations, financial intermediation, paper products and publishing, construction, and transport. U.S. lumber is important, most likely for pallets to ship fruits and vegetables, as well as the chemical industry, for its fertilizers and pesticides and plastic packaging. The top ten CSS represent $69 \%$ of the worker hours in the fruit and vegetable supply chain.

\subsection{Social Hotspot Database Modeling of the Strawberry Yogurt Supply Chain}

The two primary CSS of interest, the dairy products and fruit and vegetables sectors in the U.S., may generate moderate social impacts in the supply chain. According to the SHDB, the issues with very high risk at the country level in the U.S. are: (1) the country's refusal to ratify international labor conventions and (2) its deficiencies in collective bargaining rights for workers. Freedom of Association and the Right to Strike are also not well recognized. At the sector-specific level for the growing of vegetables and fruits in the U.S., wages might not be adequate in keeping unskilled workers above the non-poverty guideline set by the International Labor Rights Forum [23]. There is also the limited risk of forced labor within this particular sector. Specifically for dairy production in the U.S., for all the characterized SHDB issues, this sector has only low or medium risk.

The supply chain, or cradle-to-gate life cycle, of strawberry yogurt was more thoroughly examined by modeling two separate CSS lists within the SHDB, one from the Worker Hours Assessment and another from an external review of the supply chain. From the Worker Hours Assessment, the top 200 CSS were analyzed from the dairy product sector analysis ( $89 \%$ of total worker hours) and the top $50 \mathrm{CSS}$ were tested from the vegetable and fruit product analysis ( $83 \%$ of total worker hours). The results of the SHDB modeling of these CSS indicate that, specifically for the top ten CSS, the Hotspot Index (HI) is the highest for oil seeds from India $(\mathrm{HI}=87)$, and ranges from approximately 38-45 for the U.S. sectors. The dairy product manufacturing has the lowest Hotspot Index and the highest is for corn and other grains used to feed the cows. Raw milk production falls in the middle with a Hotspot Index of 42. Since production activities for U.S.-made strawberry yogurt ranking highest in the worker hours assessment occur primarily within the U.S., they are important to assess for social issues, even if sectors within the U.S. have a lower Hotspot Index compared to other countries. 
Since the GTAP model's sector classifications are not granular enough to evaluate yogurt and strawberries specifically (sectors of dairy production and vegetables, fruits and nuts were used, respectively), a second list was developed based on a literature review of the life cycle's main production activities and their potential locations. This list included countries that export yogurt ingredients (i.e., starches, gelatin, sugar, fruits), packaging products (i.e., plastic containers, aluminum foil), and fossil fuels (i.e., oil, pesticides) to the U.S. The review resulted in 159 CSS to be tested in the model. The full second list is reported in the Social Scoping Assessment [20].

The results from analysis of the second list of CSS indicate that while most of the CSS were captured in the top 200 Worker Hour CSS, the lack of granularity of the GTAP model may cause certain CSS to be overlooked. The Hotspot Indexes (100 being the most susceptible to social issues, as in the case of Angola oil extraction), as well as the worker hour rankings in the dairy products sector (the lower the number, the higher the rank), are shown for the CSS obtained via literature review (Table 2). In most cases, if the Worker Hours rank is less than 200, then the CSS was evaluated in the Worker Hours Assessments. In a few cases, important CSS were not captured in the initial assessment.

Table 2. Top Country-specific Sectors (CSS) most at risk for social issues to be present based on a literature review of the most important CSS in the supply chain of strawberry yogurt.

\begin{tabular}{cccc}
\hline Country & Sector Description & $\begin{array}{c}\text { Hotspot Index } \\
\mathbf{( 0 - 1 0 0 )}\end{array}$ & $\begin{array}{c}\text { Worker Hours Rank in } \\
\text { dairy sector } \\
\text { (out 6441 CSS) }\end{array}$ \\
\hline Angola & Oil extraction & 100.00 & 48 \\
China & Chemical products, plastics & 75.11 & 92 \\
India & Live animal products, gelatin & 73.33 & 96 \\
Indonesia & Chemical products, plastics & 72.15 & 135 \\
India & Sugarcane, beet sugar & 66.67 & 166 \\
India & Mining of metal ores & 66.67 & 61 \\
China & Coal mining, refining & 63.87 & 17 \\
Venezuela & Oil extraction & 63.73 & 99 \\
China & Other food products, starches & 62.33 & 50 \\
China & Vegetables \& Fruits & 61.51 & 215 \\
India & Chemical products, plastics & 60.42 & 203 \\
Turkmenistan & Gas extraction & 58.59 & 367 \\
China & Petroleum products-fertilizers, pesticides & 57.78 & 183 \\
China & Live animals, gelatin & 55.91 & 356 \\
Philippines & Vegetables \& Fruits & 54.55 & 63 \\
Venezuela & Chemical products, plastics & 53.85 & 56 \\
Mexico & Vegetables \& Fruits & 45.56 &
\end{tabular}

In order to choose hotspots for strawberry yogurt's supply chain, it was necessary to evaluate both the Hotspot Indexes and the Worker Hours ranks for all CSS. For example, although Philippines' Vegetable and Fruits sector has a higher hotspot index than Mexico's, it is noticeably lower on the Worker Hours Rank, thus Mexico is a more important hotspot to consider. Strawberries may very well be imported from Mexico when California strawberries are out of season. Added ingredients such as gelatin from India or China, or starches from China, can be at risk of social impacts. Sugar, in particular from India, also bares significant risk. Chemical products, including plastic containers and 
fertilizers/pesticides, also represent important risk when originating in countries like China, Venezuela, and Indonesia. Fossil fuel extraction and mining sectors represent a large share of the worker hours and are extremely susceptible to social issues and, particularly for society and local communities, but also for workers.

\subsection{Supporting Literature Including Initiatives, Certifications and Campaigns}

Information obtained in a literature review of reports and documents offering information on the main social issues found in the strawberry yogurt life cycle is presented along with the SHDB results of CSS most at risk for Social Hotspots. The literature review supported the modeling results by confirming that the issues identified using the SHDB are truly a concern, indicating where they might occur in the production of strawberry yogurt from cradle-to-gate. The additional information gained from the review will be used to make expert judgments on the most pertinent social issues. The social issues distinguished in the countries and sectors of interest include:

- Worker rights such as inadequate housing and transport, lack of transparency from labor contractors, exclusion from unemployment insurance and prevention of collective bargaining may be an issue for some hired dairy workers [24].

- Local food production, maintaining a community's agriculture heritage, recreational access, charitable activities (donation of time and money), as well as farm "nuisances" like flies and odor are among the most important community social issues for the dairy sector [25].

- Large amounts of pesticide and insecticide are being applied to strawberries that can affect the health and safety of workers and neighboring communities [26].

- Occupational safety and heat stress protections, denial of rest and meal periods, unpaid overtime and minimum wages, retaliation and wrongful termination as well as sexual harassment are violations most commonly reported for California Specialty crops farming operations [24].

A high number of the media campaigns compiled reflects that several issues pertaining to dairy farms and strawberries were brought to the attention of the public in recent years. It supports the social issues literature review and the social hotspots assessment of working conditions in the specialty crops and dairy sector especially regarding freedom of association and collective bargaining rights, infringement of workers rights and health and safety risk related to pesticide and insecticide use. A limited number of certifications are available for strawberries, sugar and dairies. Ingredients often need to be organic in order to obtain a "fair" certification. One of the most important initiatives related to strawberry yogurt is the U.S. Stewardship Index for Specialty Crops. 


\subsection{Identification of Hotspots in the Strawberry Yogurt Life Cycle}

Results of the two SHDB assessments, in combination with the literature review of social issues and media campaigns, indicate what production activities and countries may be hotspots in the strawberry yogurt life cycle and what social issues are the most important to look for. Dairy and strawberry production are both responsible for a very large amount of the worker hours in the strawberry yogurt supply chain. They are important to assess for social issues using the SHDB, even if sectors within the U.S. have a lower probability for social impacts compared to other countries. Issues occurring in countries like China, India, Venezuela, Indonesia and Mexico are more probable. Table 3 offers a selection of the countries and sectors to be aware of in the supply chain based on the results of the SHDB assessments and literature review.

The CSS were selected as hotspots if:

- They are responsible for a large share of the worker hours.

- They are at high risk for social issues based on the Hotspot Index.

- They were identified by multiple sources including media campaigns.

Table 3. Sectors and countries most at risk to be hotspots in the supply chain for Strawberry Yogurt produced in the U.S.

\begin{tabular}{cc}
\hline Sectors to Be Aware of: & Countries to Be Aware of within Sector: \\
\hline Raw Milk, Dairy Products, Business Services & USA \\
Vegetables and Fruits-strawberries & USA, Mexico \\
Corn and other cereal grains & USA \\
Animal products-gelatin & India, China \\
Other foods-starches & China \\
Sugarcane, beet sugar, oil seeds & India \\
Chemical products-containers, food additives & China, Venezuela, Indonesia \\
Petroleum products-fertilizers & China \\
\hline
\end{tabular}

Figure 1 offers a visual representation of several CSS recommended as hotspots in the strawberry yogurt supply chain. The risk levels for the most relevant social issues are indicated around the spider plot, but many more were measured using the SHDB. However, all 20 Social Themes were assessed with results for over 50 indicators. See Table 1 (or 2) for the complete list of characterized issues. To view the graph properly, only a selection of CSS and a selection of social issues are shown. The legend shows a selection of CSS chosen as hotspots for strawberry yogurt. The scale is defined as: $0=$ no data or no evidence, $1=$ low, $2=$ medium, $3=$ high, and $4=$ very high risk.

The results of the SSA indicate that social issues do occur in the strawberry yogurt supply chain, and that companies producing and marketing yogurt should be aware of particular countries and sectors where the opportunity for social improvements exists. Because the worker hours are concentrated mostly in the U.S., which has a fairly low level of social issues compared to other less developed economies, U.S. strawberry yogurt production can show rapid improvement if it addresses the social issues within the country, primarily in the arena of labor rights. The social issues with very high risk at in the U.S. are: (1) the country's refusal to ratify international labor conventions and (2) its deficiencies in collective bargaining rights for workers. Freedom of Association and the Right to Strike 
are also not well recognized. At the sector-specific level for the growing of vegetable and fruit in the U.S., wages might not be adequate in keeping unskilled workers above the non-poverty guideline set by the Labor Rights Forum [23]. There is also the risk of forced labor within this particular sector. Specifically for dairy production in the U.S., for all issues, this sector has only low or medium risk.

Figure 1. Plot of the prominent social issues present in particular countries and sectors involved in the supply chain of Strawberry Yogurt.

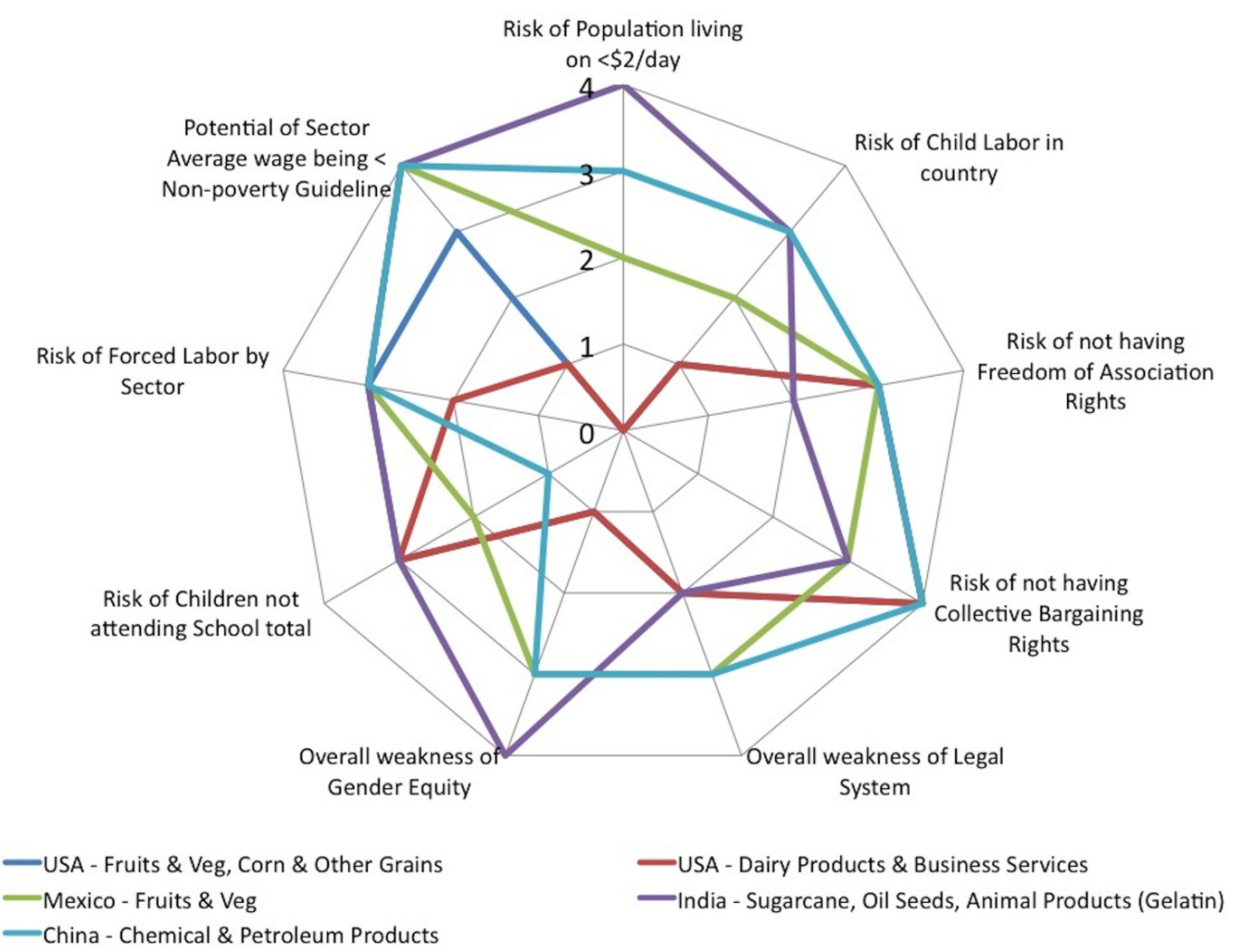

Other countries and sectors with a significant share of the labor time for strawberry yogurt produced in the U.S., like fresh strawberries from Mexico and agricultural and food additive chemical products and plastic containers from China and Venezuela, as well as those CSS slightly further down in the worker hours ranking with high Hotspot Indexes, such as sugar from India and starches from China, do require major improvements in the social sphere. Gender equity in these countries, as well as low wages and lack of worker's rights, are prominent issues. Child and forced labor is certainly prevalent. And the countries' legal systems are most likely inadequate in protecting the workers or the local communities.

\subsection{Limitations of the Social Hotspot Database and Social Scoping Assessment}

The Social Scoping Assessment Reports faced three notable limitations: (1) a lack of granularity in the GTAP model; (2) unavailability of uncertainty and data quality indicators for the social issue data; and (3) limited published research on social impacts specific to countries and sectors.

The SHDB system utilizes a Global IO model derived from GTAP [15]. This Global IO model is comprised of a matrix of 57 sectors and 113 countries and regions. A model at a greater level of 
granularity would generate more precise results, like for specific fruits and vegetables (e.g., strawberries) rather than an aggregate; but such a detailed global IO model is not available at the present time. In order to compensate for this limitation and make the assessment more specific, a second list of CSS was compiled from a literature review based on external research of the supply chain.

The second shortcoming of the SHDB is its lack of an uncertainty assessment or data quality indicators for the data in the Social Theme Tables. Both of these types of statistical data analyses are important to the validity of the model and are planned for future work. Data quality was an important consideration in choosing indicators for the Tables, however, as was highlighted in the list of criteria delineated in Section 2.1.

Data is inconsistently available from the literature to assess the potential social impacts of the main ingredients/inputs of most products. For instance, while data may be available for strawberry farming, information on social impacts in the production of fertilizers is scarce. Furthermore, often the topic of the journal article is not directly related to social hotspot identification, and the data is often coming from secondary, "unverified" sources or underfunded governmental agencies. However, these inadequacies in the literature only point to the need for more top-down, overarching supply chain modeling as offered by the SHDB.

Table 4. Future Research needs identified for the SHDB.

\begin{tabular}{|c|c|}
\hline I/O Model & $\begin{array}{l}\text { - Improve the granularity of the I/O model and the global coverage. } \\
\text { - Conduct peer review of the I/O and worker hours model. }\end{array}$ \\
\hline Data & $\begin{array}{l}\text { - Expand the set of themes included in the database. } \\
\text { - Include more positive impacts themes and data. } \\
\text { - Enhance collaboration on data with relevant organizations. } \\
\text { - Conduct peer review of the Social Theme Tables. } \\
\text { - Develop further the economic sector of activities social impacts data. } \\
\text { - Research, develop and add uncertainty assessment and data } \\
\text { - } \text { Add information about improvement opportunities related to the hotspots. } \\
\text { - Develop data for more granular I/O and unit process models. } \\
\text { - Conduct meta-analysis on the data and the results generated by the assessments. }\end{array}$ \\
\hline Hotspots index & $\begin{array}{l}\text { - Conduct sensitivity analysis on the results. } \\
\text { - Integrate multi attribute assessment methods. } \\
\text { - Enable stakeholder participation in index creation. } \\
\text { - Research and add other prioritization criteria. } \\
\text { - Develop a positive impact index. }\end{array}$ \\
\hline $\begin{array}{l}\text { Characterization } \\
\text { models }\end{array}$ & - Refine the characterization models with expert input. \\
\hline Case studies & $\begin{array}{l}\text { - Conduct several complete LCA case studies starting with a SHDB assessment, } \\
\text { involving site-specific data collection activities on hotspots and ending with a final } \\
\text { impact assessment step. } \\
\text { - Test the model on a large number of product categories. }\end{array}$ \\
\hline Visualization & $\begin{array}{l}\text { Develop tools and graphs that are visually appealing and summarize } \\
\text { the results effectively. }\end{array}$ \\
\hline
\end{tabular}




\subsection{Research Needs}

The section above outlined several limitations and challenges stemming from various characteristics of the Social Hotspots Database, the Social Scoping Assessment and the status of availability and development of social data. Many of the current limitations and challenges could be resolved in the future. Table 4 details research opportunities that would enhance the Social Hotspots Database system and also more generally support the continuous development of Social LCA.

\section{Conclusion}

S-LCA is a technique developed to enable the assessment of potential and verified social impacts within product life cycles. Ultimately, it aims to inform the improvement of the social conditions of production. As businesses are increasingly encouraged, and in some instances required, to show progress regarding their product supply chains sustainability impacts, S-LCA is considered to be one of the most relevant methods available.

The SHDB represents an actionable system to assess the social hotspots of product life cycles. It was developed over a period of 3 years as a follow-up project to the UNEP SETAC Guidelines for S-LCA. A first version of the SHDB was created over this time and the content is expanding. It is composed of a global worker hour assessment model and 20 Social Theme Tables. It offers characterized indicator data on 191 countries and multiple sectors where applicable and modeling capabilities for 113 countries and regions and 57 sectors. The data was collected from over 200 data sources including mostly international organizations' secondary databases. In the future, the information available will be more granular and supported by uncertainty and data quality assessments. The SHDB Social Theme Tables' references and characterization methods are fully transparent and detailed documentation on all of the Social Theme Tables can be accessed from the project website [27].

Because a very large amount of information is provided by a social hotspot assessment, there was a need to further refine the hotspots assessment to prioritize only a smaller subset of CSS. In order to achieve the required level of refinement, a Hotspot Index was developed to calculate the cumulative level of risk as well as the labor intensity of each CSS.

The SHDB system was piloted for 7 product categories in a project mandated by The Sustainability Consortium. For each of the product categories, a social scoping assessment report was developed. The reports included findings generated from modeling and literature reviews. This paper highlights one of the product categories assessed, strawberry yogurt produced and sold in the U.S. [20].

The results of the SSA for strawberry yogurt indicate that social issues do occur in the strawberry yogurt supply chain, and that companies producing and marketing yogurt should be aware of particular countries and sectors where the opportunity for social improvements exists. The assessment enabled prioritization of a small number of CSS and highlighted specific social issues to be aware of in those CSS as a first step to further research activities.

The SHDB is a system that can be used to prioritize site-specific data collection activities and to put site-specific results in perspective. However, it is not a system to be used to make sourcing decisions directly since there will always be more hotspots to address. Because every country and sector has 
potential impacts, shifting production from one country to another on this basis would be counterproductive. Site-specific data are required to inform decision-making and to help improve the social performance of at-risk node of the supply chain. In any case, it is always worth pursuing active engagement in improving the existing conditions [28].

The availability, quality and sources of information on social impacts of product supply chains is currently very limited and in many cases inexistent. The SHDB provides results that increase the visibility in product category supply chains by modeling the product system and presenting social issue information. The results of this first phase testing the SHDB has lead The Sustainability Consortium to mandate an additional 100 product category social hotspots studies that are forthcoming.

In summary, the SHDB system has shown value as an innovative tool that offers top down visualization of a product supply chain's potential social impacts. The research needs section has highlighted several research opportunities that will enhance the system and its application and support Social LCA development. As we shed light on the social impacts of production, we will need to find and propose workable solutions that will improve the social conditions in those areas where they are most vulnerable.

\section{Acknowledgments}

The authors would like to thank the organizations that supported the creation, the development and the application of the Social Hotspots Database: The Sustainability Consortium, United Nations Environment Programme, Wal Mart Private brands, Pepsi co, ECPAR, University of New Hampshire, University of Arkansas, Carnegie Mellon University and New Earth. Also a special thank you to all the research assistants that made the Social Hotspots Database come to life and allowed New Earth to meet tight project deadlines, in particular Caroline Hallisey-Kepka, Isabelle Altman, Susan Overraker, John Reed, Nick Tamblyn, Shannon Rogers and Gina Vickery Niederman. Finally, this project hugely benefited from the contribution of the New Earth board of advisors composed of 25 representatives from the academia, business, NGO and governmental sectors.

\section{Conflict of Interest}

The authors declare no conflict of interest.

\section{References}

1. Goleman, D. Ecological Intelligence: The Hidden Impacts of What We Buy, 1st ed.; Doubleday: New York, NY, USA, 2009.

2. Chouinard, Y.; Ellison, J.; Ridgeway, R. The Big Idea: The Sustainable Economy; Harvard Business Review; Harvard Business: Boston, MA, USA, October 2011.

3. BSR. Overview of corporate social responsibility. Available online: http://www.bsr.org (accessed on 31 October 2011).

4. Parmigiani, A.; Klassen, R.; Russo, M. Efficiency meets accountability: Performance implications of supply chain configuration, control, and capabilities. J. Oper. Manag. 2011, 29, 212-223. 
5. California State Senate. SB 657. California Transparency in Supply Chains Act of 2010. Available online: http://leginfo.ca.gov/pub/09-10/bill/sen/sb_0651-0700/sb_657_bill_ 20100930_chaptered.html (accessed on 31 October 2011).

6. United Nations Human Rights. The Corporate Responsibility to Respect Human Rights: An Interpretive Guide; United Nations: New York, NY, USA, 2012. Available online: http://www.ohchr.org/Documents/Issues/Business/RtRInterpretativeGuide.pdf (accessed on 31 October 2011).

7. United Nations. Supply Chain Sustainability: A Practical Guide for Continuous Improvement. Available online: http://www.bsr.org/reports/BSR_UNGC_SupplyChainReport.pdf (accessed on 31 October 2011).

8. International Organization for Standardization (ISO). Environmental Management-Life Cycle Assessment_-Requirements and Guidelines; ISO 14040:2006; International Organization (ISO): Geneva, Switzerland, 2006.

9. Norris, G.A. Social impacts in product life cycles: Towards life cycle attribute assessment. Int. J. Life Cycle Assess. 2006, 11, 97-104.

10. Benoît, C.; Mazijn, B. Guidelines for Social Life Cycle Assessment of Products; UNEP/SETAC Life Cycle Initiative, Sustainable Product and Consumption Branch: Paris, France, 2009.

11. Kloepffer, W. Life-Cycle based methods for sustainable product development. Int. J. Life Cycle Assess. 2003, 8, 157-159.

12. Hauschild, M.Z.; Dreyer, L.C.; Jørgensen, A. Assessing social impacts in a life cycle perspective-Lessons learned. Manuf. Technol. 2008, 57, 21-24.

13. United Nations Environment Programme (UNEP)/SETAC. Towards a life cycle sustainability assessment: Making informed choices on products.; UNEP/SETAC Life Cycle Initiative, Sustainable Product and Consumption Branch: Paris, France, 2011.

14. Ekvall, T. Nations in social LCA. Int. J. Life Cycle Assess. 2011, 16, 1-2.

15. Purdue University. Global Trade Analysis Project (GTAP): GTAP 7 data base. Available online: https://www.gtap.agecon.purdue.edu/databases/default.asp (accessed on 2 January 2008).

16. International Labor Organisation (ILO). Laborsta internet. Available online: http://www. laborsta.ilo.org/ (accessed on 2 January 2008).

17. United Nations Industrial Development Organization (UNIDO). Available online: http://www. unido.org (accessed on 2 January 2008).

18. Organization for Cooperation and Development's Stat Extracts (OECD). OECD statistics. Available online: http://www.stats.oecd.org (accessed on 2 January 2008).

19. Food and Agriculture Organization. Rural Income Generating Activities (RIGA) Database. Available online: http://www.fao.org (accessed on 2 January 2008).

20. Benoit, C.; Aulisio, D.; Hallisey-Kepka, C.; Tamblyn, N.; Norris, G.A. Social scoping prototype report for strawberry yogurt, the sustainability consortium. Available online: http://www. socialhotspot.org (accessed on 1 March 2012).

21. Schultz, M. Dairy products profile. Agricultural Marketing Resource Center. Available online: http://www.agmrc.org/commodities_products/livestock/dairy/dairy_products_profile.cfm (accessed on 12 April 2011). 
22. Romanowski, P. How products are made: Yogurt. Available online: http://enotes.com/howproducts-encyclopedia/yogurt (accessed on 12 April 2011).

23. International Labor Organization (ILO). Non-Poverty wages for countries around the world. Available online: http://www.ci.mil.wi.us/ImageLibrary/Groups/doaPurchasing/forms/ nonpovertywage.pdf (accessed on 8 May 2009).

24. Bon Appetit Management Company (BAMC). Foundation united farm workers, inventory of farmworker issues and protections in the United States. Available online: www.ufw.org/pdf/farmworkerinventory_0401_2011.pdf (accessed on 12 April 2011).

25. Manomet Center for Conservation Sciences. Got Milk (For Four Billion)? Available online: http://www.manomet.org/news/20110330/got-milk-four-billion (accessed on 12 April 2011).

26. Calvin, L.; Martin, P.; Waves, A. Labor-Intensive U.S. fruit, vegetable industry competes in global market. Available online: http://westernfarmpress.com/orchard-crops/labor-intensive-usfruit-vegetable-industry-competes-global-market?page=2 (accessed on 15 April 2011).

27. Benoit, C.; Norris, G.; Aulisio, D.; Rogers, S.; Reed, J.; Overaker, S. Social hotspots database: Risk and opportunity table development. Available online: http:/www.socialhotspot.org/userfiles/ SHDB_Risk_And_Opportunity_Tables_-_Final_Fall_2010.pdf (accessed on 1 March 2010).

28. Locke, R.; Amengual, M.; Mangla, A. Virtue out of necessity? Compliance, commitment, and the improvement of labor conditions in global supply chains. Polit. Soc. 2009, 37, 319-351.

(C) 2012 by the authors; licensee MDPI, Basel, Switzerland. This article is an open access article distributed under the terms and conditions of the Creative Commons Attribution license (http://creativecommons.org/licenses/by/3.0/). 